\title{
Reversible dilated Cardiomyopathy caused by Wilms tumour - a case report
}

\author{
Arshed Hussain Parry, Naseer Ahmed Choh, Abdul Haseeb Wani, Irfan Robbani
}

Department of Radio diagnosis, SKIMS

\section{A B S T R A C T}

Two year-old female child presented with abdominal distension and respiratory distress, on evaluation was found to have dilated cardiomyopathy (DCM) associated with Wilms tumourin absence of hypertension. The patient was given neo-adjuvant chemotherapy with eventual reduction in size of primary tumour which led to improvement in cardiac function. The patient subsequently underwent nephrectomy with return of cardiac function to normal.

Keywords: Wilms tumours, Nephroblastoma, dilated cardiomyopathy.

JMS: 2019; 22(3):27-29 DOI: https://doi.org/10.33883/jms.v22i3.456

\section{INTRODUCTION}

Wilms tumour (nephroblastoma) constitutes the most common paediatric renal tumour accounting for $80-90 \%$ of paediatric renal tumors and 12 percent of childhood cancers. It is rare during the first year of life and is commonly seen between 1-5 years of age with a peak incidence at 3 years ${ }^{1}$. Wilms tumour usually presents with slow growing abdominal mass. Cardiovascular complications of Wilms tumour are well known and include congestive cardiac failure (due to hypertension caused by the pressure of the tumour on hilar or intra-renal vessels) or intra-cardiac extension of a tumour thrombus. However, it is quite unusual of nephroblastoma to cause dilated cardiomyopathy without hypertension ${ }^{2,3}$.

\section{CASE HISTORY}

Two year-old female child presented to out-patient department with abdominal distension, episodic respiratory distress and decreased food intake for last 1 month. On examination, the child was awake, febrile $\left(38^{\circ} \mathrm{C}\right)$ with blood pressure $88 / 48 \mathrm{~mm} \mathrm{Hg}$.Her weight was $11 \mathrm{~kg}$.

\begin{tabular}{|l|l|} 
& Access this article online \\
Website: & \\
\end{tabular}

Cardiopulmonary auscultation finding was normal. Abdominal palpation revealed mass in the right hypochondrium which was moving with respiration. Chest radiograph revealed cardiomegaly. The electrocardiogram showed normal sinus rhythm with left ventricular hypertrophy. Echocardiography noted hypokinetic dilated cardiomyopathy with an ejection fraction of $25 \%$, with grade 2 mitral regurgitation, without heart defect or intracardiac thrombus. Abdominal USG revealed heterogeneous mass arising from upper pole of right kidney with tiny calcifications. Renal vein appeared normal. Abdominal CT findings were consistent with right nephroblastoma. There was no evidence of distant metastasis. Contrast MRI abdomen revealed findings consistent with right sided Wilms tumour (Fig.1a, 1b and 1c). Cardiac MRI confirmed

Correspondence:

Dr.Arshed Hussain Parry, MD

Senior Resident, Department of Radio diagnosis, SKIMS

Contact Phone Number: +917006179927

ContactEmail: arshedparry@gmail.com

How to cite this article: Parry A, Choh NA, Wani AH, Robbani I. Reversible dilated cardiomyopathy caused by Wilms Tumour - a case report. jms 2019;22(3):27-29

Received: 03-05-2019 Accepted: 12-10-2019 Published: 
Parry AH; et al; Reversible dilated Cardiomyopathy caused by Wilms tumour - a case report

the above findings of echocardiography (Fig 2a, 2b). Blood screen was normal except for high plasma renin activity (38 $\mathrm{ng} / \mathrm{ml} /$ hour $)$ and angiotensin II $(52 \mathrm{nmol} / \mathrm{ml} / \mathrm{min}$.). Percutaneous ultrasound guided biopsy of renal mass was done which revealed blastemmal predominant type of Wilms tumour (Fig. 1d). Owing to the underlying DCM surgery was delayed and patient was started on chemotherapy. After 3 doses of etoposide and carboplatin patient was again reassessed. Tumour burden had significantly decreased with significant improvement in cardiac function. The patient subsequently underwent right nephrectomy. The histopathology was typical of an intermediate risk nephroblastoma, classified as International Society of Paediatric Oncology stage 1 with nephrogenic rests. Postoperative chemotherapy was started with Vincristine and Actinomycin D.

\section{DISCUSSION}

Most children present with a painless abdominal mass often discovered accidentally by the parents or by the physician on a routine examination. Fever, malaise, anorexia and gross or microscopic hematuria may occur. Wilms tumour is well known to cause cardiovascular complications either in the form of extension of tumour thrombus into right atrium via inferior vena cava (IVC) or by the mass effect of tumour on renal hilar vessels. Compression on renal hilar vessels leads to hypertension which could ultimately lead to congestive heart failure. Dilated cardiomyopathy in the absence of hypertension is very rarely encountered complication in nephroblastoma. The association of DCM with nephroblastoma has been reported only few times. In 2003, 2 cases of nephroblastoma with dilated cardiomyopathy without hypertension were reported by Trebo et. $\mathrm{al}^{5}$. The reported cases had a diminished cardiac function at the time of presentation which gradually returned to normal after nephrectomy. In 2017 Emmanuelle Chalavon et.al ${ }^{6}$ reported another case of 7 month old baby with markedly reduced cardiac function. But upon completion of treatment cardiac function returned to normal. Our patient was troubled by episodic bouts of respiratory distress. Echocardiography revealed decreased cardiac functions with ejection fraction of $25 \%$. The patient was treated with neoadjuvant chemotherapy which led to regression in tumour burden. Finally patient was subjected to right nephrectomy. Upon completion of treatment the patient recorded return of cardiac function to normal. The association of DCM with neuroblatoma is well known and occurs due to over production of catecholamines by the tumour which lead to heightened blood pressure and subsequently to heart failure ${ }^{7,8}$. Wilms tumour does not cause hypertension by the production of catecholamines but due to compression of renal vessels at hilum. However, occurrence of DCM in Wilms tumour patients in the absence of hypertension is extremely uncommon and has been found to occur by an alternate mechanism namely, secondary to secretion of renin and angiotensin by the tumour cells. Our case also demonstrated raised levels of renin and angiotensin with absence of hypertension. Treatment of primary tumour initially with chemotherapy and later by radical surgery resulted in return of cardiac functions to normal which substantiates the fact that reversible DCM can be caused by Wilms tumour in the absence of hypertension.

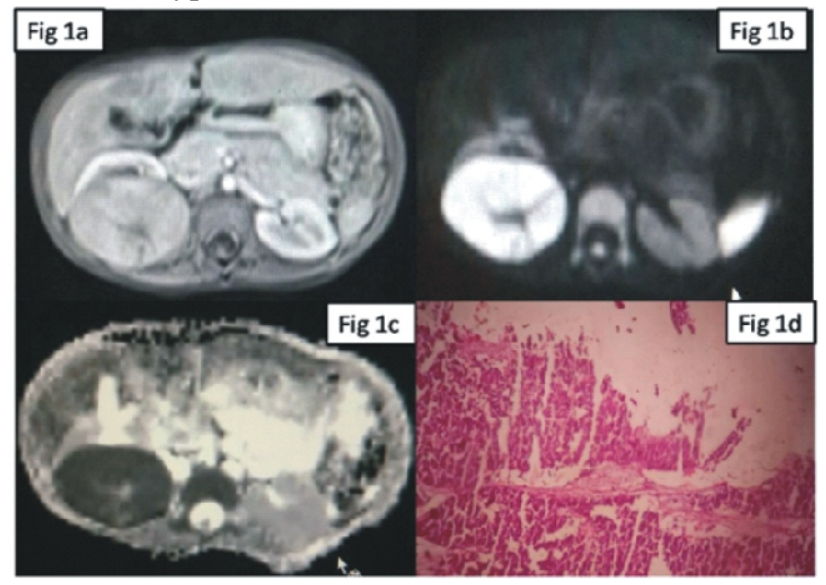

Figure 1: Post contrast MRI image (Fig. 1a) showing homogenously enhancing right renal mass with central small nonenhancing area. Diffusion weighted image (Fig. 1b) with corresponding ADC map. (Fig. 1c) showing diffusion restriction within mass except for small central region. Histopathology (Fig. 1d) showing Wilms tumour (Blastemal predominant).

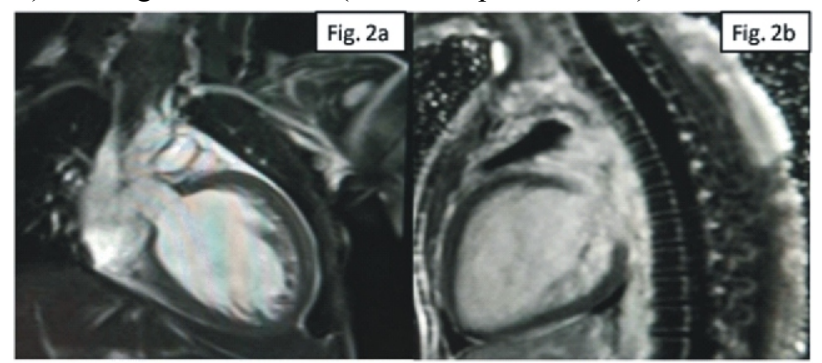

Figure 2: TRUFI coronal (a) and sagittal (b) cardiac images show dilated left ventricle. 
Parry AH; et al; Reversible dilated Cardiomyopathy caused by Wilms tumour - a case report

\section{REFERENCES}

1. Geller E, Smergel EM, Lowry PA. Renal neoplasms of childhood. RCNA 1997; 35(6):1391-1413.

2. Agarwala B, Mehrotra N, Waldman JD. Congestive Heart Failure Caused by Wilms' Tumor. Pediatric cardiology. 1997 Jan 1; 18(1):43-4.

3. Akyüz C, Emir S, Büyükpamukçu N, Atahan L, Çaglar M, Kutluk T, Büyükpamukçu M. Cavoatrial tumor extension in children with Wilms tumor: a retrospective review of 17 children in a single center. Journal of pediatric hematology/oncology. 2005 May 1;27(5):267-9.

4. Lonergan GJ, Martinez-Leon MI, Agrons GA, Montemarano H,Suarez ES. Nephrogenic rests, nephroblastomatosis, and associatedlesions of the kidney. RadioGraphics 1998; 18:947-968.
5. TreboMM, Mann G, Dworzak M, etal.Wilmstumor and cardiomyopathy. Med PediatrOncol. 2003;41:574

6. Chalavon E, Lampin ME, Lervat C, Leroy X, Bonnevalle M, Recher M, Sudour-Bonnange $\mathrm{H}$. Dilated Cardiomyopathy Caused by Wilms Tumor. Pediatric emergency care. 2017 Jan 1;33(1):41-2.

7. Kato M, Hirata S, Kikuchi A, Ogawa K, Kishimoto H, Hanada R. Neuroblastoma presenting with dilated cardiomyopathy. Pediatric blood \& cancer. 2008 Feb; 50(2):391-2.

8. Duhil de Bénazé G, Iserin F, Durand P, Schleiermacher G, Orbach D. A Dilated Cardiomyopathy Revealing a Neuroblastoma: Which Link? J PediatrHematolOncol. 2016;38(7):e251-253. 